\title{
Development of Sarcocystis falcatula in cell cultures demonstrates that it is different from Sarcocystis neurona
}

\author{
D. S. LINDSAY ${ }^{1 *}$, J. P. DUBEY ${ }^{2}$, K. M. HORTON ${ }^{3}$ and D. D. BOWMAN ${ }^{3}$ \\ ${ }^{1}$ Center for Molecular Medicine and Infectious Diseases, Department of Biomedical Sciences and Pathobiology, \\ Virginia-Maryland Regional College of Veterinary Medicine, Virginia Tech, 1410 Prices Fork Road, Blacksburg, \\ Virginia 24061-0342, USA \\ ${ }^{2}$ United States Department of Agriculture, Agricultural Research Service, Livestock and Poultry Sciences Institute, \\ Parasite Biology and Epidemiology Laboratory, Beltsville, Maryland 20705-2350, USA \\ ${ }^{3}$ Department of Microbiology and Immunology, College of Veterinary Medicine, Cornell University, Ithaca, \\ New York 14853-6401, USA
}

(Received 20 August 1998 ; revised 16 September 1998; accepted 17 September 1998)

\section{SUM MARY}

The development of Sarcocystis falcatula merozoites in bovine turbinate (BT) cell cultures is described and compared with development of Sarcocystis neurona merozoites. Merozoites of S. falcatula entered BT cell cultures and increased in size until 3 days post-inoculation when the nucleus of some merozoites developed lobes. Developing schizonts present at 4 days contained a lobed nucleus or appeared multinucleate. A single mature schizont was observed 4 days p.i. Schizonts were numerous 5 and 6 days p.i. Merozoites were produced from blastophores on the schizont. S. neurona merozoites developed to mature schizonts by 3 days p.i. in BT cells and a residual body was often present. Transmission electron microscopy revealed that $S$. falcatula merozoites possessed more micronemes than did $S$. neurona merozoites. Our study demonstrates that $S$. falcatula and $S$. neurona are not the same parasite.

Key words: Sarcocystis falcatula, Sarcocystis neurona, coccidia, schizonts, merozoites, cell culture.

\section{INTRODUCTION}

Sarcocystis falcatula Stiles, 1893 is a protozoan parasite with birds as intermediate hosts and the opossum, Didelphis virginiana as the definitive host (Box \& Duszynski, 1978). It has an unusually wide intermediate host range for a Sarcocystis species (Box \& Smith, 1982). Sarcocystis falcatula is highly pathogenic for several species of pet birds and outbreaks of fatal infections have been reported in birds raised in outdoor aviaries (Clubb \& Frenkel, 1992) and in collections of psittacines in zoos (Hillyer et al. 1991). The opossum is its only known definitive host for S. falcatula (Box, Meier \& Smith, 1984).

Equine protozoal myeloencephalitis (EPM) is a neuralgic syndrome seen in horses from the Americas and is caused by infection with $S$. neurona Dubey, Davis, Speer, Bowman, de Lahunta, Granstrom, Topper, Hamir \& Suter, 1991 (Dubey et al. 1991). The condition has been recognized for over 20 years and EPM is the most important protozoal disease of horses in the United States (MacKay, 1997). Recent

\footnotetext{
* Corresponding author: Center for Molecular Medicine and Infectious Diseases, Department of Biomedical Sciences and Pathobiology, Virginia-Maryland Regional College of Veterinary Medicine, Virginia Tech, 1410 Prices Fork Road, Blacksburg, Virginia 24061-0342, USA. Tel: +5402316302. Fax: +540231 3426. E-mail: lindsayd@vt.edu
}

serological surveys indicate that $45-53 \%$ of horses have antibodies to $S$. neurona (Bentz, Gramstrom \& Stamper, 1997; Blythe et al. 1997; Saville et al. 1997).

Studies using the small subunit ribosomal RNA sequences have indicated that $S$. falcatula and $S$. neurona were the same parasite (Dame et al. 1995; Fenger et al. 1995). However, conclusive biological demonstration that the two are the same species is lacking. Results of the study reported here do not support the assumption that the two species are the same. We demonstrate that the in vitro development of S. falcatula is different from that of S. neurona.

\section{MATERIALS AND METHODS}

Sarcocystis neurona SN2 strain merozoites (Davis, Daft \& Dubey (1991) isolated from a horse with EPM and $S$. falcatula Cornell strain merozoites (isolated from the lungs of a budgerigar, Melopsittacus undulatus, fed sporocysts from an opossum) were grown and maintained in bovine turbinate cells (B'T cells, ATTC CRL 1390, American Type Culture Collection, Rockville, Maryland, USA). The BT cells were grown to confluence in $25 \mathrm{~cm}^{2}$ plastic cell culture flasks in growth medium consisting of $10 \%(\mathrm{v} / \mathrm{v})$ foetal bovine serum (FBS) in RPMI-1640 medium supplemented with $100 \mathrm{U}$ penicillin $\mathrm{G} / \mathrm{ml}$, and $100 \mathrm{mg}$ streptomycin $/ \mathrm{ml}$. Cell 


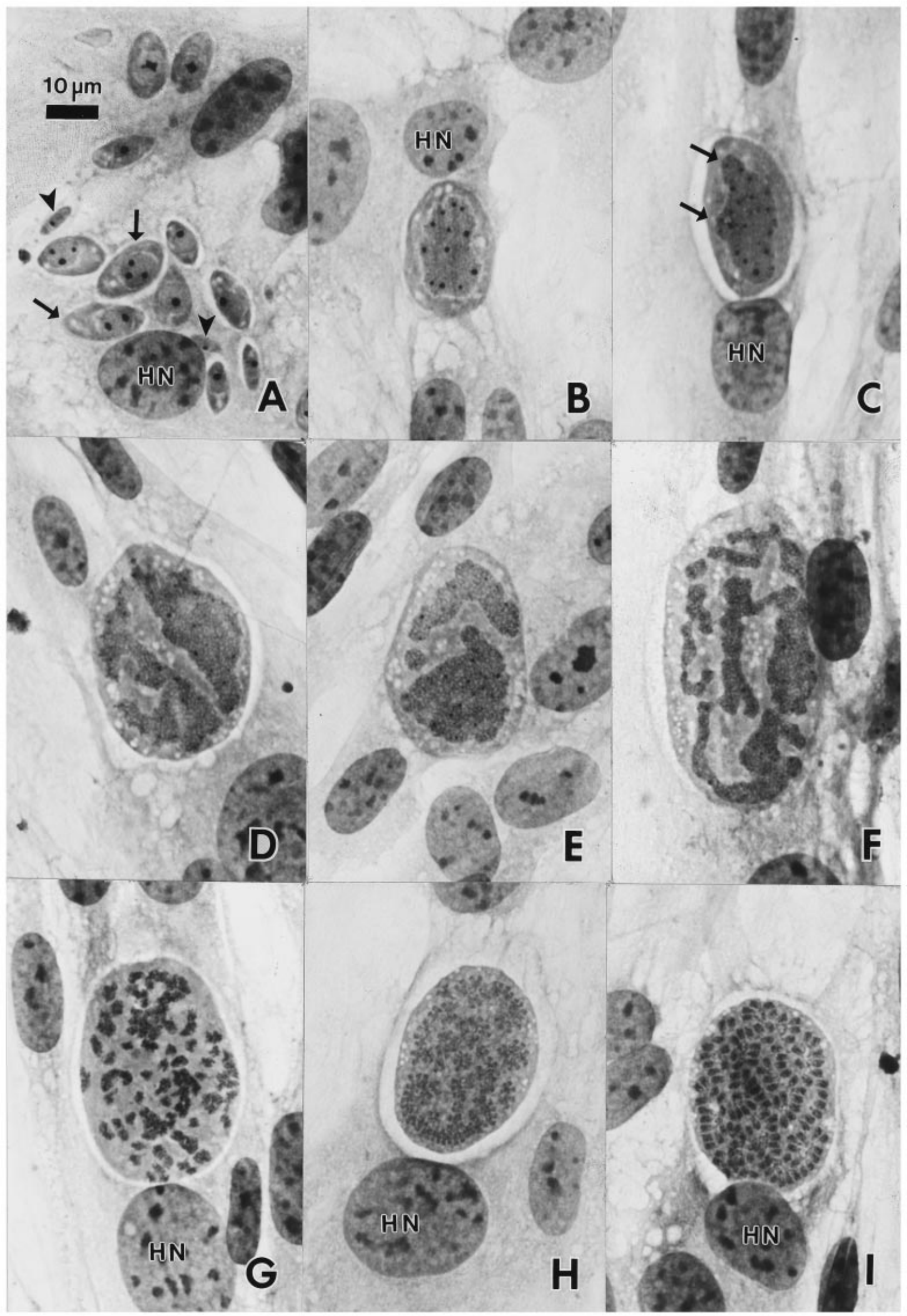

Fig. 1. For legend see opposite. 


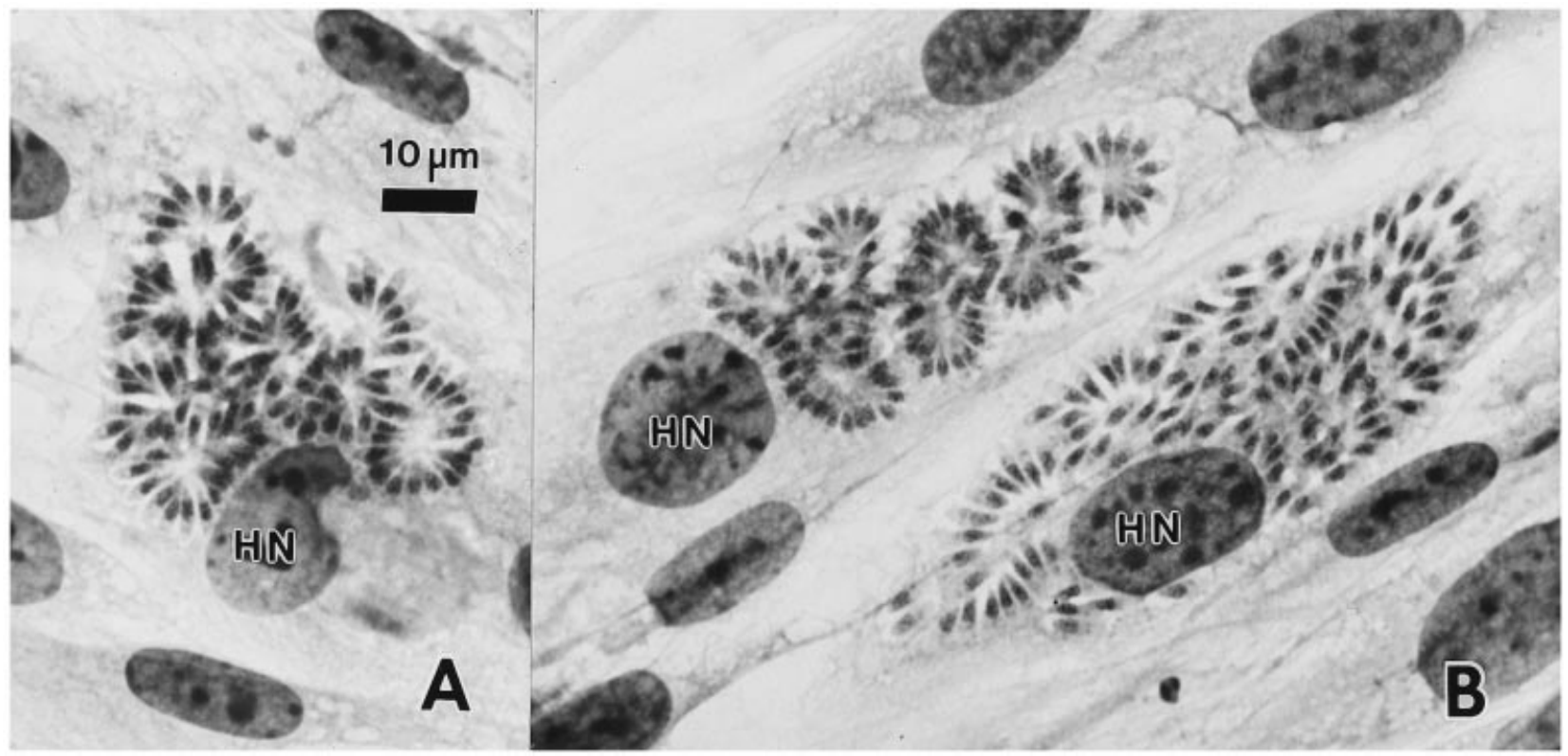

Fig. 2. (A and B) Mature schizonts of Sarcocystis falcatula. All 6 days p.i. (A) Schizont demonstrating merozoites originating from 4-5 blastophores. Note the absence of a residual body. (B) Schizont demonstrating merozoites originating from 8 blastophores directly above a schizont that contains merozoites which no longer appear to be associated with blastophores. HN, host cell nucleus.

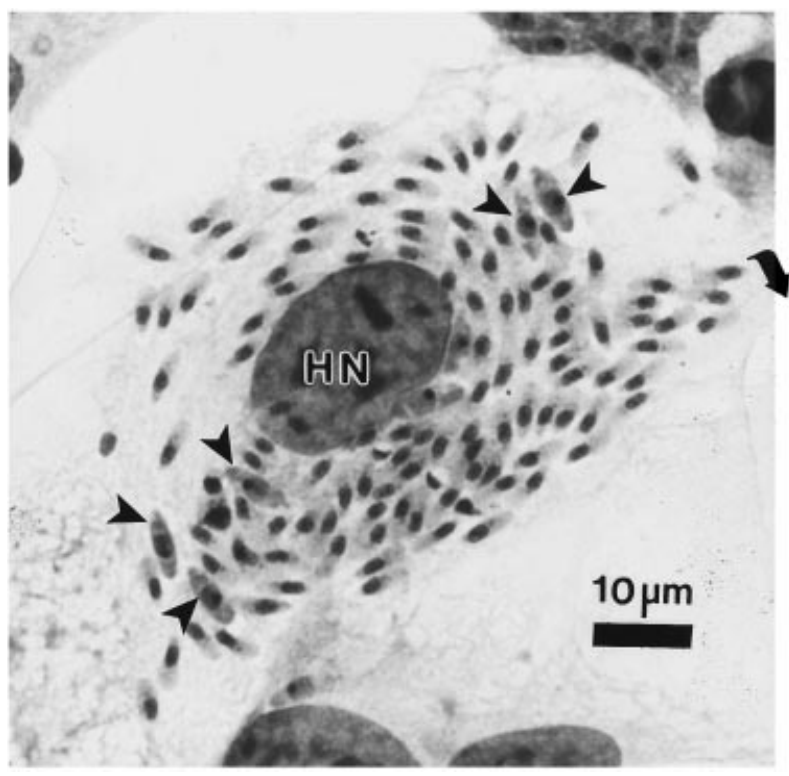

Fig. 3. Mature schizont of Sarcocystis falcatula in which the merozoites are arranged in a circular pattern around the host cell nucleus (HCN). Several of the merozoites (arrowheads) have begun to enlarge. Six days p.i. HN, host cell nucleus. cultures were maintained in growth medium in which the FBS content was lowered to $2 \%$. Cell cultures were incubated at $37{ }^{\circ} \mathrm{C}$ in a humidified atmosphere containing $5 \% \mathrm{CO}_{2}$ and $95 \%$ air. For descriptive studies, merozoites were harvested from infected cell cultures by removing the medium and replacing it with Hanks' balanced salt solution without calcium and magnesium. The BT cells were then removed from the plastic growth surface by use of a cell scraper. This cell mixture was passed through a 27-gauge needle attached to a $10 \mathrm{ml}$ syringe to rupture host cells. The suspension was then filtered through a sterile $3 \mu \mathrm{m}$ filter to remove cellular debris. The number of merozoites in the filtrate was determined using a haemocytometer. From $0 \cdot 2$ to $1 \cdot 0 \times 10^{6}$ merozoites of S. falcatula were used as inoculum and from $1 \cdot 0$ to $2 \cdot 0 \times 10^{5}$ merozoites of $S$. neurona were used. The merozoites were inoculated onto $22 \mathrm{~mm}^{2}$ glass coverslips containing a monolayer of B'T cells in 6-well tissue culture plates.

Cover-slips were removed on days 1, 2, 3, 4, 5 and 6 p.i., fixed in $10 \%$ phosphate-buffered formalin for $30 \mathrm{~min}$, placed in $100 \%$ methanol for $10 \mathrm{~min}$ and stained with a Giemsa-type stain. Cover-slips were

Fig. 1. (A-I) Development from merozoites to immature schizonts of Sarcocystis falcatula. All 6 days p.i.

(A) Multiply infected cell that demonstrates merozoites (arrowheads) and several developing schizonts. Note the 2-3 prominent nucleoli in some of the larger stages (arrows). (B) Developing schizont in which the nucleus occupies about $80 \%$ of the cytoplasm and contains 12 nucleoli. (C) Schizont with a nucleus that is beginning to develop lobes (arrows). (D and E) Schizonts, each with a nucleus that is highly folded, giving the appearance of grooves in the nucleus. (F) Advanced schizont demonstrating more pronounced nuclear changes than shown in (D) or (E). (G and $\mathrm{H})$ Schizonts each with a nucleus that is in advanced stages of condensing. (I) Schizont with numerous nuclei that have segregated into developing merozoites. HN, host cell nucleus. 


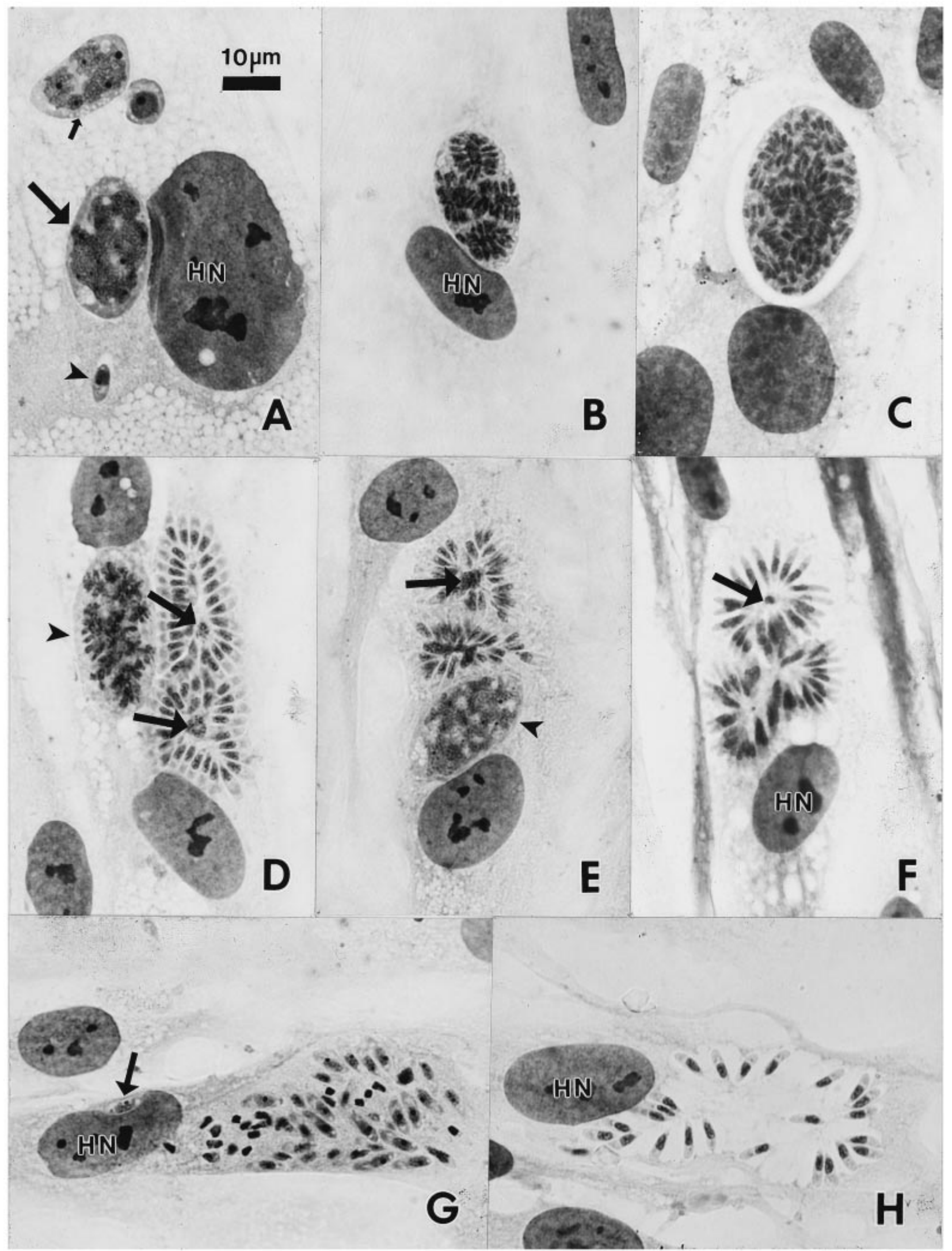

Fig. 4. (A-H) Developing and mature schizonts of Sarcocystis neurona. All 6 days p.i. (A) Host cell containing a merozoite (arrowhead), a developing schizont (small arrow) and a developing schizont with a lobed nucleus (large arrow). (B and C) Developing schizonts demonstrating condensing nuclei prior to merozoite formation. (D and E) Developing schizonts (arrowheads) adjacent to mature schizonts with merozoites being produced at blastophores. Note the residual body (arrows). (F) Mature schizont clearly demonstrating a residual body (arrow). (G) Host cell that contains randomly arranged merozoites. Note a merozoite (arrow) has indented the host cell nucleus. (H) Host cell similar to $(\mathrm{G})$ in which a majority of the merozoites has escaped. HN, host cell nucleus. 


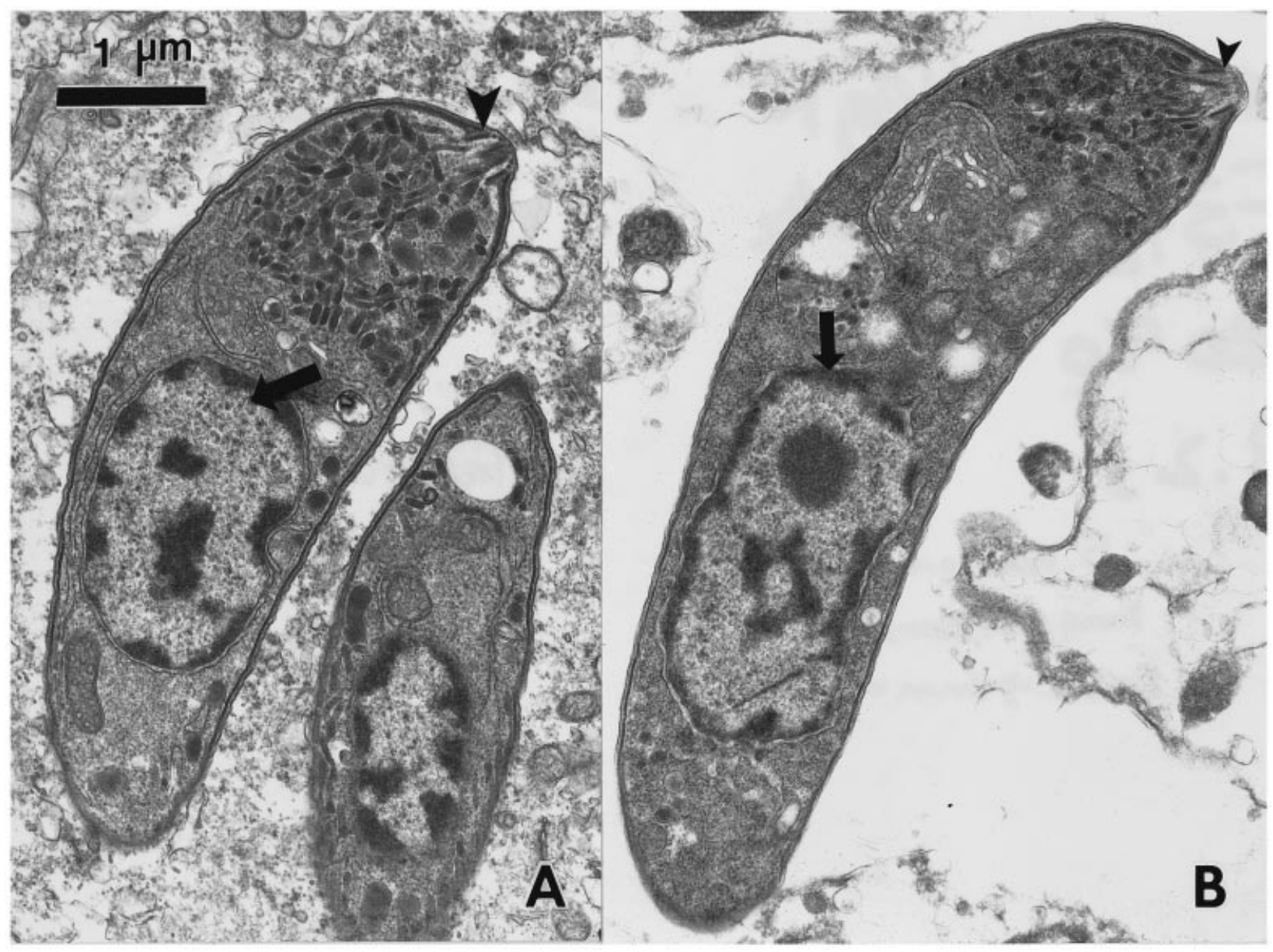

Fig. 5. (A and B) TEM of merozoites of Sarcocystis falcatula and Sarcocystis neurona. (A) Longitudinal section through S. falcatula. Note the conoid (arrowhead), absence of rhoptries, and the numerous micronemes which extend three-quarters of the way to the nucleus (arrow). (B) Longitudinal section through S. neurona. Note the conoid (arrowhead), absence of rhoptries, and the numerous micronemes which extend one-quarter of the way to the nucleus (arrow).

attached to glass microscope slides with Permount ${ }^{\circledR}$ (Fisher Scientific, Fairlawn, New Jersey, USA) and examined with light microscopy. Stages were measured with a calibrated ocular micrometer. Measurements are expressed in $\mu \mathrm{m}$ as the mean followed by the range and number $(N)$ of stages measured in parenthesis.

Transmission electron microscopy was done on cultures 16 days p.i. The BT cells were scraped from the growth surface, pelleted by centrifugation, and fixed in $2.5 \%$ glutaraldehyde in $0.1 \mathrm{~m}$ sodium cacodylate buffer $(\mathrm{pH} 7 \cdot 2)$. The pellet was post-fixed in $2 \%(\mathrm{w} / \mathrm{v})$ osmium tetroxide, dehydrated in a series of ethanols, passed twice through propylene oxide and embedded in Epon/Araldite (Polysciences, Inc., Warrington, Pennsylvania, USA). Thin sections were stained in uranyl acetate and lead citrate and examined using a Philips TEM 201 transmission electron microscope operating at $80 \mathrm{kV}$.

RESULTS

Sarcocystis falcatula merozoites entered BT cells and underwent schizogony within 4 days (Figs 1-3).
Parasites were usually located next to the host cell nucleus. Occasionally parasites appeared to be in the host cell nucleus. Division was asynchronous resulting in cells containing structurally different organisms. Intracellular merozoites measuring 7.9 by $2 \cdot 4(6 \cdot 4-10 \cdot 4$ by $1 \cdot 6-4 \cdot 0, N=20)$ were the only stages observed for $S$. falcatula 1 day p.i. Merozoites grew in size and were $10 \cdot 6$ by $5 \cdot 1(8 \cdot 0-16 \cdot 0$ by $1 \cdot 6-8 \cdot 0$, $N=20) 2$ days p.i. The nucleus of some merozoites became lobed (Fig. 1) by 3 days p.i. and these developing schizonts were $17 \cdot 4$ by $10 \cdot 4(10 \cdot 4-30 \cdot 4$ by $4 \cdot 6-18 \cdot 4, N=25)$. The nucleoli were prominent in these stages. The nucleus of schizonts underwent additional transformations to form groves, lobes and projections and eventually portions of the nucleus were incorporated into merozoites as a single nucleus. A single mature schizont was seen 4 days p.i. Four merozoites were 5.6 by 1.6 . They contained a posteriorly located nucleus. Numerous developing schizonts and mature schizonts were seen 5 and 6 days p.i. (Figs 2 and 3). Merozoites were formed at blastophores which developed on the schizont surface prior to cytokenesis. A residual body was not seen. Developing schizonts present 5 days p.i. were 
$37 \cdot 3$ by $24 \cdot 6(33 \cdot 6-44 \cdot 0$ by $20 \cdot 0-30 \cdot 4, \quad N=20)$. Merozoites present 5 days p.i. were 6.3 by 1.6 (5.6-7.2 by $1 \cdot 2-2 \cdot 4, N=20)$. Developing schizonts present 6 days p.i. were $36 \cdot 6$ by $24 \cdot 6(27 \cdot 2-44 \cdot 0$ by $17 \cdot 6-32 \cdot 0, N=20)$. Merozoites present 6 days p.i. were $6 \cdot 6$ by $1 \cdot 8(5 \cdot 6-8 \cdot 0$ by $1 \cdot 6-2 \cdot 4, N=20)$.

Sarcocystis neurona merozoites entered BT cells and underwent schizogony within 3 days (Fig. 4). Parasites were usually located next to the host cell nucleus. Occasionally parasites appeared to be in the host cell nucleus. Division was asynchronous resulting in cells containing structurally different organisms. Intracellular merozoites measuring $7 \cdot 9$ by $2 \cdot 9(6 \cdot 4-11.2$ by $1 \cdot 6-4 \cdot 0, N=20)$ were the only stages observed for $S$. neurona 1 day p.i. Merozoites increased in size and became developing schizonts. Merozoites with a lobed nucleus were observed 2 days p.i. and these developing schizonts were 12.9 by $5 \cdot 4(8 \cdot 8-20 \cdot 8$ by $2 \cdot 4-11 \cdot 2, N=20)$. Developing and mature schizonts were present at 3 days p.i. The developing schizonts were $24 \cdot 6$ by $12 \cdot 9(16 \cdot 0-32 \cdot 8$ by $7 \cdot 2-17 \cdot 6, N=20)$. Merozoites in mature schizonts had a posteriorly located nucleus and were 6.7 by 1.5 $(5 \cdot 6-7 \cdot 2$ by $1 \cdot 2-1 \cdot 6, N=15)$ at 3 days p.i. Merozoites were formed at blastophores which developed on the schizont surface prior to cytokenesis. A residual body was often visible in mature schizonts observed 3-6 days p.i. Developing schizonts present at 4 days were $27 \cdot 6$ by $15 \cdot 2(20 \cdot 0-41 \cdot 6$ by $11 \cdot 2-18 \cdot 4, N=20)$. Merozoites in mature schizonts were 5.8 by 1.7 $(4 \cdot 8-6 \cdot 4$ by $1 \cdot 6-2 \cdot 4, N=20)$ at 4 days p.i. Developing schizonts present at 5 days were $26 \cdot 2$ by $14 \cdot 2$ $(20 \cdot 0-40 \cdot 0$ by $11 \cdot 2-17 \cdot 6, \quad N=20)$. Merozoites in mature schizonts were $5 \cdot 6$ by $1 \cdot 7(4 \cdot 8-6 \cdot 4$ by $1 \cdot 6-2 \cdot 4$, $N=20)$ at 5 days p.i. Developing schizonts present at 6 days were $24 \cdot 2$ by $13 \cdot 7(17 \cdot 6-30 \cdot 4$ by $10 \cdot 4-18 \cdot 4$, $N=20$ ). Merozoites in mature schizonts were 5.8 by $1 \cdot 6(4 \cdot 8-6 \cdot 4$ by $1 \cdot 6, N=20)$ at 6 days p.i.

Transmission electron microscopy revealed that both parasites developed in the cytoplasm of the host cell. Merozoites of S. falcatula (Fig. 5) contained a conoid, lacked rhoptries, had numerous micronemes which extended three-quarters of the way to the nucleus and had 22 subpelicular microtubules and other organelles typical for apicomplexan merozoites. Merozoites of S. neurona (Fig. 5) contained a conoid, lacked rhoptries, had micronemes which extended one-quarter the way to nucleus and had 22 subpelicular microtubules and other organelles typical for apicomplexan merozoites.

\section{DISCUSSION}

Our study demonstrates structural and developmental differences between $S$. falcatula and $S$. neurona using light microscopy and TEM. The most striking difference observed with light microscopy was the larger size of developing $S$. falcatula schizonts, the longer developmental period needed for schizogony of S. falcatula, and the absence of a residual body in mature $S$. falcatula schizonts. Our TEM observations indicate that S. falcatula has more micronemes and they extend farther towards the merozoite nucleus than the micronemes of $S$. neurona. Results of our study do not support the contention based on small subunit ribosomal RNA sequences (Dame et al. 1995; Fenger et al. 1995) that the 2 parasites are the same. Additional genetic analysis of $S$. falcatula and $S$. neurona is needed to determine if genetic markers can be used to differentiate the 2 species.

Research on potential vaccines for EPM should be done with isolates that come from clinically ill horses. This will assure that the appropriate immunodominant antigens will be identified. Likewise, generation of cDNA or gDNA libraries for potential vaccines should be done with isolates of $S$. neurona from clinically ill horses.

This study was funded in part by a grant from the Equine Health Research Fund (EHRF) of the American Horse Shows Association (AHSA) to D.S.L., and a grant from the Harry M. Zweig Memorial Fund for Equine Research to D.D.B.

\section{REFERENCES}

Bentz, B. G., GRAnStrom, D. E. \& STAMPER, s. (1997).

Seroprevalence of antibodies to Sarcocystis neurona in horses residing in a county of southeastern Pennsylvania. Fournal of the American Veterinary Medical Association 210, 517-518.

Blythe, L. L., GRANSTrom, D. E., HANSEN, D. E., WALKer, L. L., BARTLETT, J. \& STAMPER, S. (1997).

Seroprevalence of antibodies to Sarcocystis neurona in horses residing in Oregon. Fournal of the American Veterinary Medical Association 210, 482-483.

BOx, E. D. \& DUSZYNSKi, D. W. (1978). Experimental transmission of Sarcocystis from icterid birds to sparrows and canaries by sporocysts from the opossum. Fournal of Parasitology 64, 682-688.

BOX, E. D. \& SMith, J. H. (1982). Intermediate host spectrum in a Sarcocystis species of birds. Fournal of Parasitology 68, 668-673.

BOX, E. D., MEIER, J. L. \& SMith, J. H. (1984). Description of Sarcocystis falcatula Stiles, 1893, a parasite of birds and opossums. Fournal of Protozoology 31, 521-524.

ClubB, S. L. \& FRENKEL, J. K. (1992). Sarcocystis falcatula of opossums: Transmission by cockroaches with fatal pulmonary disease in psittacine birds. Fournal of Parasitology 78, 116-124.

Davis, s. W., DAFT, B. M. \& DUBEy, J. P. (1991). Sarcocystis neurona cultured in vitro from a horse with equine protozoal myelitis. Equine Veterinary Fournal 23, 315-317.

DAME, J. B., MackAY, R. L., YOWELl, C. A., CUTlER, T. J., MARSH, A. \& GREINER, E. C. (1995). Sarcocystis falcatula from passerine and psittacine birds: Synonymy with Sarcocystis neurona, agent of equine protozoal myeloencephalitis. Fournal of Parasitology 81, 930-935.

DUbey, J. P., DAvis, S. W., SPEer, C. A., BOWMAN, D. D., DE 
LAHUNTA, A., GRANSTROM, D. E., TOPPER, M. J., HAMIR, A. N. \& SUTER, M. M. (1991). Sarcocystis neurona n. sp. (Protozoa: Apicomplexa), the etiologic agent of equine protozoal myeloencephalitis. Fournal of Parasitology 77, 212-218.

FENGER, C, K., GRANSTROM, D. E., LANGEMEIER, J. L., STAMPER, S., DONAHUE, J. M., PATTERSON, J. S., GAJADHAR, A. A., MARTENIUK, J. V., XiAOMin, Z. \& DUBEY, J. P. (1995). Identification of opossums (Didelphis virginiana) as the putative definitive host of Sarcocystis neurona. Fournal of Parasitology $\mathbf{8 1}$, 916-919.
HILLYER, E. V., ANDERSON, M. P., GREINER, E. C., ATKINSON, C. T. \& FRENKEL, J. K. (1991). An outbreak of Sarcocystis in a collection of psittacines. Fournal of Zoo and Wildlife Medicine 22, 434-445.

MACKAY, R. L. (1997). Equine protozoal myloencephalitis. Veterinary Clinics of North America Equine Practice 13, 79-96.

SAlville, W. J., REED, S. M., GRANSTROM, D. E., HiNCHLifF, K. W., KOHN, C. W., Wittum, T. E. \& stamper, s. (1997). Seroprevalence of antibodies to Sarcocystis neurona in horses residing in Ohio. Fournal of the American Veterinary Medical Association 210, 519-524. 